\title{
A modified M-stage classification based on the metastatic patterns of pancreatic neuroendocrine neoplasms: a population-based study
}

Xianbin Zhang ${ }^{1,2^{*}+}$ D, Jiaxin Song ${ }^{3+}$, Peng Liu' ${ }^{1}$, Mohammad Abdul Mazid ${ }^{1}$, Lili Lu ${ }^{3}$, Yuru Shang ${ }^{1}$, Yushan Wei ${ }^{4}$, Peng Gong ${ }^{5}$ and Li Ma ${ }^{3,6^{*}}$

\begin{abstract}
Background: The present study aims to improve the M-stage classification of pancreatic neuroendocrine neoplasms (pNENs).

Methods: Two thousand six hundred sixty six pNENs were extracted from the Surveillance, Epidemiology, and End Results database to explore the metastatic patterns of pNENs. Metastatic patterns were categorized as single, two, or multiple (three or more) distant organ metastasis. The mean overall survival and hazard rate of different metastatic patterns were calculated by Kaplan-Meier and Cox proportional hazards models, respectively. The discriminatory capability of the modified M-stage classification was evaluated by Harrell's concordance index.

Results: The overall survival time significantly decreased with an increasing number of metastatic organs. In addition, pNENs with only liver metastasis had better prognosis when compared to other metastatic patterns. Thus, we modified the M-stage classification ( $\mathrm{mM}$-stage) as follows: $\mathrm{mM}_{0}$-stage, tumor without metastasis; $\mathrm{mM}_{1}$-stage, tumor only metastasized to liver; $\mathrm{mM}_{2}$-stage, tumor metastasized to other single distant organ (lung, bone, or brain) or two distant organs; $\mathrm{mM}_{3}$-stage, tumor metastasized to three or more distant organs. Harrell's concordance index showed that the modified M-stage classification had superior discriminatory capability than both the American Joint Committee on Cancer (AJCC) and the European Neuroendocrine Tumor Society (ENETS) M-stage classifications.

Conclusions: The modified M-stage classification is superior to both AJCC and ENETS M-stage classifications in the prognosis of pNENs. In the future, individualized treatment and follow-up programs should be explored for patients with distinct metastatic patterns.
\end{abstract}

Keywords: Metastasis, Survival, Prognosis, Pancreas, Cancer

\section{Background}

Pancreatic neuroendocrine neoplasms (pNENs) are relatively rare tumors. However, a recent population study showed that the incidence of pNENs increased more than 4-fold from 1973 to 2012 [1]. Moreover, pNENs are considered the most serious neuroendocrine neoplasms

\footnotetext{
* Correspondence: zhangxianbin@hotmail.com; mali_lele@sina.com

${ }^{+}$Xianbin Zhang and Jiaxin Song contributed equally to this work.

${ }^{1}$ The First Affiliated Hospital of Dalian Medical University, Zhongshan 222,

Dalian 116011, China

${ }^{3}$ Department of Epidemiology, Dalian Medical University, Lvshun West 9,

Dalian 116044, China

Full list of author information is available at the end of the article
}

(NENs), due to the patients have a shorter median overall survival times (3.6 years) when compared to those with tumors located in lung (5.5 years), rectum (24.6 years), and appendix (more than 30.0 years) [1].

Cancer staging classification systems are used to codify the extent of cancer. They allow clinicians to quantify prognosis and plan treatment for individual patients. Two widely used tumor staging classification systems, which are proposed by the American Joint Committee on Cancer (AJCC) and the European Neuroendocrine Tumor Society (ENETS), describe $\mathrm{M}_{0}$-stage as having no distant metastasis and $\mathrm{M}_{1}$-stage as having at least one

(c) The Author(s). 2018 Open Access This article is distributed under the terms of the Creative Commons Attribution 4.0 International License (http://creativecommons.org/licenses/by/4.0/), which permits unrestricted use, distribution, and reproduction in any medium, provided you give appropriate credit to the original author(s) and the source, provide a link to the Creative Commons license, and indicate if changes were made. The Creative Commons Public Domain Dedication waiver (http://creativecommons.org/publicdomain/zero/1.0/) applies to the data made available in this article, unless otherwise stated. 
distant metastasis [2, 3]. However, several studies demonstrated that pNENs with liver metastasis have better prognosis than other metastatic patterns [4-6].

Therefore, we utilized the Surveillance, Epidemiology, and End Result (SEER) database to explore the prognosis of different metastatic patterns of pNENs and propose a modified M-stage classification. This modified M-stage classification proves to be superior to both AJCC and ENETS M-stage classifications in prognosis.

\section{Methods}

\section{Study cohort}

As published previously [3], we utilized the topography codes (C25.0 to C25.9) and histology codes $(8150,8151$, $8152,8153,8154,8155,8156,8157,8240,8241,8242$, $8243,8244,8245,8246$, and 8249 ) of the International Classification of Diseases for Oncology (third edition) to identify pNENs.

\section{Outcomes and variables}

The primary outcome was overall survival. Demographic data included age, sex, and race; tumor characteristics included tumor size, primary site, differentiation, 7th AJCC T-stage, and N-stage; treatment information included surgery and radiotherapy. Single organ metastasis was defined as the tumor spreading from pancreas to another single distant organ [7]. Similarly, two organ metastases were defined as the tumor spreading from pancreas to two distant organs. Tumors spreading from pancreas to three or more distant organs were defined as multiple metastases.

\section{Inclusion and exclusion criteria}

Patients microscopically diagnosed as pNENs were included in the present study. We excluded cases with unclear or incomplete information about metastasis. In addition, we also excluded cases without information about survival time.

\section{Statistical analyses}

To compare the constituent ratio of variables among patients, we broke the continuous variables (age, tumor size) into binary variables. Survival time was plotted using the Kaplan-Meier estimator and Cox proportional hazards model. The results were presented as mean and hazard ratio, respectively, each with a 95\% confidence interval (CI). Harrell's concordance index was used to evaluate the discriminatory capability of the modified $M$ stage classification. An index value of greater than 0.70 suggests the classification has an acceptable discriminatory capability [8]. Differences with $P \leq 0.05$ divided by the number of meaningful comparisons, Bonferroni correction, were considered to be significant. Differences with $P \leq 0.1$ divided by the number of meaningful comparisons, were considered to indicate a tendency. All statistical analyses were performed using SPSS 19.0 (IBM, New York, USA) or R (version 3.5.0).

\section{Results \\ Patient characteristics}

In total, 2666 patients (mean age 60.9 years \pm 13.6 years; $55.7 \%$ male, $78.8 \%$ white) were included in the present study (Fig. 1). Many patients (55.4\%) underwent surgery, and some $(4.7 \%)$ were treated with radiation. The constituent ratios of tumor size, location, differentiation, $\mathrm{T}$-stage, and $\mathrm{N}$-stage were significantly $(P<0.05)$ different between patients with and without metastasis (Table 1).

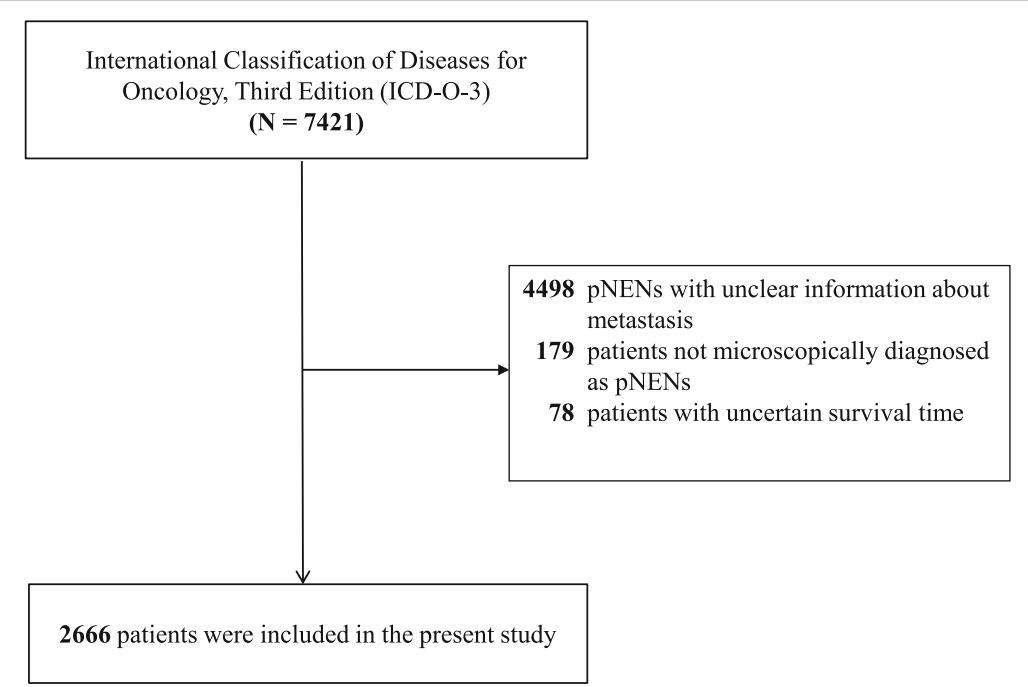

Fig. 1 Flow chart of patient selection 
Table 1 Clinicopathological Characters

\begin{tabular}{|c|c|c|c|}
\hline & Without Metastasis & Metastasis & $P$ \\
\hline & $N=1679$ & $N=987$ & \\
\hline Age (years) & & & $0.221^{\mathrm{b}}$ \\
\hline$\leq 60$ & 793 (47.2\%) & 442 (44.8\%) & \\
\hline$>60$ & $886(52.8 \%)$ & $545(55.2 \%)$ & \\
\hline Sex & & & $0.338^{\mathrm{a}}$ \\
\hline Male & 924 (55.0\%) & 562 (56.9\%) & \\
\hline Female & 755 (45.0\%) & $425(43.1 \%)$ & \\
\hline Race & & & $0.011^{\mathrm{a}}$ \\
\hline White & $1314(78.3 \%)$ & 787 (79.7\%) & \\
\hline Black & $191(11.4 \%)$ & $130(13.2 \%)$ & \\
\hline Other & $174(10.3 \%)$ & 70 (7.1\%) & \\
\hline Size $(\mathrm{cm})$ & & & $<0.001^{\mathrm{b}}$ \\
\hline$\leq 2$ & 670 (39.9\%) & $68(6.9 \%)$ & \\
\hline$>2$ & $934(55.6 \%)$ & 699 (70.8\%) & \\
\hline Unclear & $75(4.5 \%)$ & $220(22.3 \%)$ & \\
\hline Primary Site & & & $<0.001^{b}$ \\
\hline Head & $502(29.9 \%)$ & $258(26.2 \%)$ & \\
\hline Body & $295(17.6 \%)$ & 106 (10.7\%) & \\
\hline Tail & 542 (32.3\%) & 314 (31.8\%) & \\
\hline Other & $340(20.2 \%)$ & 309 (31.3\%) & \\
\hline Differentiation & & & $<0.001^{b}$ \\
\hline Well & $1043(62.1 \%)$ & 189 (19.1\%) & \\
\hline Moderately & $221(13.2 \%)$ & $86(8.7 \%)$ & \\
\hline Poorly & $64(3.8 \%)$ & $95(9.6 \%)$ & \\
\hline Undifferentiated & $17(1.0 \%)$ & $28(2.8 \%)$ & \\
\hline Unclear & 334 (19.9\%) & $589(59.7 \%)$ & \\
\hline T-sage & & & $<0.001^{\mathrm{b}}$ \\
\hline $\mathrm{T}_{1}$ & 602 (35.9\%) & 37 (3.7\%) & \\
\hline $\mathrm{T}_{2}$ & $538(32.0 \%)$ & $276(28.0 \%)$ & \\
\hline $\mathrm{T}_{3}$ & 389 (23.2\%) & 271 (27.5\%) & \\
\hline $\mathrm{T}_{4}$ & $67(4.0 \%)$ & $102(10.3 \%)$ & \\
\hline$T x$ & $83(4.9 \%)$ & 301 (30.5\%) & \\
\hline $\mathrm{N}$-stage & & & $<0.001^{\mathrm{b}}$ \\
\hline $\mathrm{N}_{0}$ & $1247(74.3 \%)$ & 463 (46.9\%) & \\
\hline $\mathrm{N}_{1}$ & 401 (23.9\%) & 338 (34.3\%) & \\
\hline Nx & $31(1.8 \%)$ & $186(18.8 \%)$ & \\
\hline Surgery & & & $<0.001^{\mathrm{b}}$ \\
\hline Yes & $1313(78.2 \%)$ & $164(16.6 \%)$ & \\
\hline No & 339 (20.2\%) & $813(82.4 \%)$ & \\
\hline Unclear & $27(1.6 \%)$ & $10(1.0 \%)$ & \\
\hline Radiation & & & $<0.001^{\mathrm{b}}$ \\
\hline Yes & $52(3.1 \%)$ & 74 (7.5\%) & \\
\hline No & $1609(95.8 \%)$ & 905 (91.7\%) & \\
\hline Unclear & $18(1.1 \%)$ & $8(0.8 \%)$ & \\
\hline
\end{tabular}

\footnotetext{
${ }^{\mathrm{a}}$ Chi-square test; ${ }^{\mathrm{b}}$ Kruskal-Wallis test
}

\section{Metastatic patterns and survival}

At the time of diagnosis, 1679 (62.98\%) patients showed no metastasis. As shown in Fig. 2a, single organ metastases comprised 850 (31.88\%) patients, including 817 liver (30.64\%), 22 lung $(0.83 \%)$, nine bone $(0.34 \%)$, and two brain $(0.07 \%)$ cases. One hundred and twelve patients (4.20\%) showed two-organ metastases, including 52 liver plus bone (1.95\%), 53 liver plus lung (1.99\%), four bone plus lung $(0.15 \%)$, two liver plus brain $(0.08 \%)$, and one bone plus brain $(0.04 \%)$ cases. Twenty-five patients (0.94\%) presented multiple organ metastases, including 19 cases of liver plus lung plus bone $(0.71 \%)$, three cases of liver plus lung plus brain $(0.11 \%)$, and three cases of liver plus lung plus brain plus bone $(0.11 \%)$.

To assess survival time of different metastatic patterns, we compared the survival time of patients without metastasis to those with single distant organ metastasis, two-organ metastases, and multiple organ metastases. As the number of metastatic organs increased, survival time was significantly $(P<0.001)$ reduced (Fig. 2 b). In addition, patients with only liver metastasis had a longer survival time than did other single-organ metastases (Fig. 2c), whereas patients with bone, lung or two-organ metastasis had similar mean survival time (bone, 18.32 months \pm 5.27 months; lung, 17.77 months \pm 3.54 months, two organs metastases, 15.79 months \pm 1.70 months).

\section{Modified M-stage classification and discriminatory capability}

Thus, based on the observed metastatic patterns and survival times, we modified the M-stage classification (mM-stage) as shown in Table 2. Tumor without metastasis was defined as $\mathrm{mM}_{0}$-stage. Tumor spread from pancreas only to liver was defined as $\mathrm{mM}_{1}$-stage. Tumor spreading from pancreas to other single distant organ or to two distant organs was defined as $\mathrm{mM}_{2}$-stage. Tumor spreading to three or more distant organs was defined as $\mathrm{mM}_{3}$-stage.

To evaluate survival time among $\mathrm{mM}$-stage classifications, survival curves were plotted using the Kaplan-Meier estimator and then compared with the log-rank test. We observed that all survival curves were well separated (Fig. 2d). Patients with advanced $\mathrm{mM}$ stages $\left(\mathrm{mM}_{1}, \mathrm{mM}_{2}, \mathrm{mM}_{3}\right)$ had significantly $(P<0.001)$ shorter survival times than patients with $\mathrm{mM}_{0}$-stage (Fig. 2e). Moreover, the modified M-stage classification was an independent prognostic factor for pNENs, after adjusting for other clinical and pathological characteristics (Table 3).

To explore discriminatory capability of the modified M-stage classification, Harrell's concordance index was calculated. The mM-stage classification had a better discriminatory capability (Harrell's concordance index, 0.712; 95\% CI, 0.692-0.732) than AJCC M-stage and 

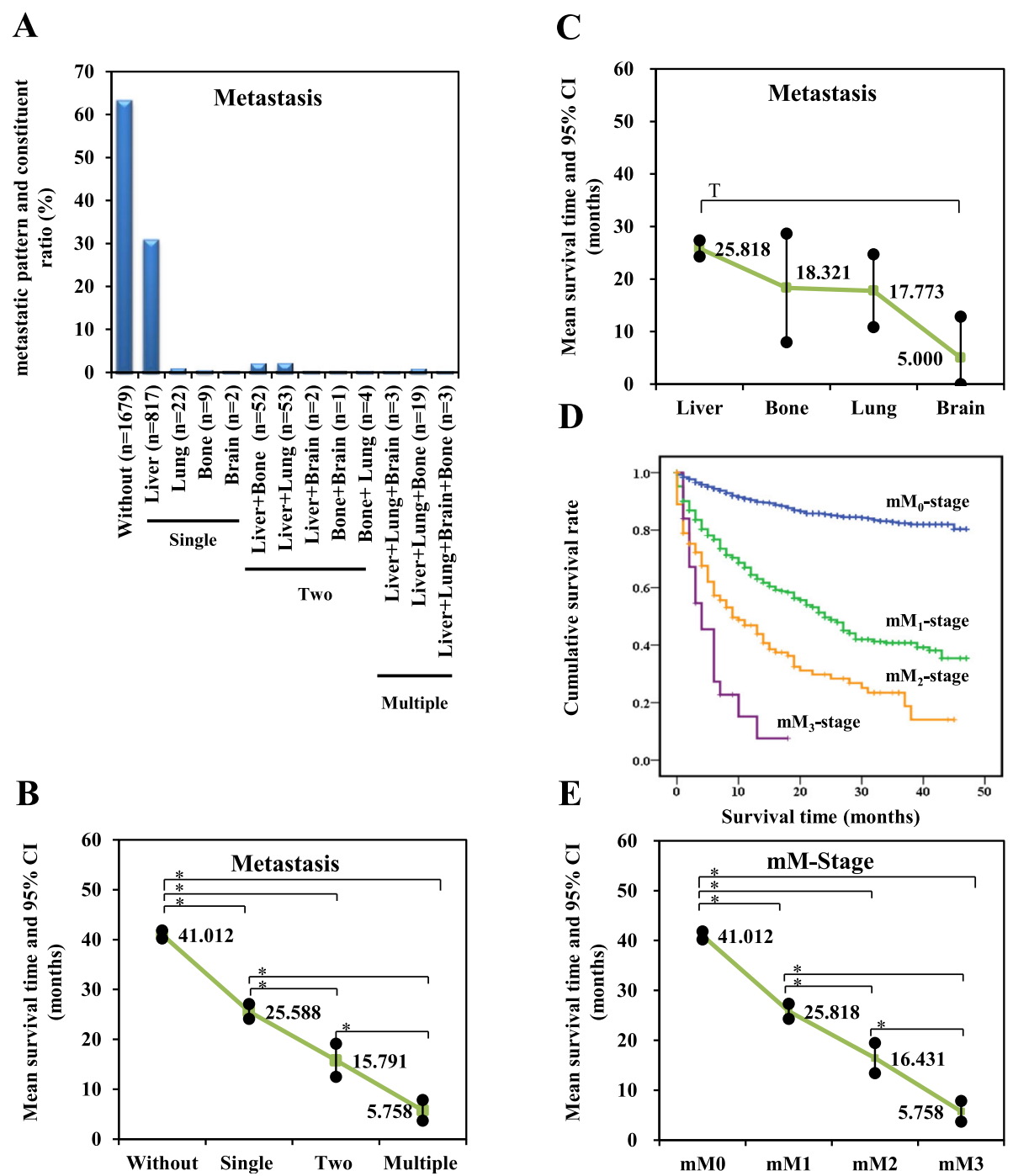

Fig. 2 a Metastatic patterns of pNENs. b Survival time of patients different metastatic patterns. c Survival time of patients with single distant organ metastasis. $\mathbf{d}$ Kaplan-Meier curve of overall survival of patients with modified M-stage classification. e Survival time of patients with modified M-stage classification. ${ }^{*}$ Significant difference: $P<0.008 ;{ }^{\top}$ Tendentious difference: $P<0.017$

ENETS M-stage (Harrell's concordance index, 0.697; 95\% CI, 0.678-0.717).

\section{Discussion}

In agreement with previous studies [9-11], the present study also demonstrated that nearly one quarter of patients (37.02\%, 987/2666) presenting metastasis at the time of pNEN diagnosis. In addition, liver metastasis was the majority metastatic pattern, followed by lung, bone and brain metastasis. The hematogenous mode of metastasis might contribute to the metastatic pattern, which we have observed in the present study. Unsually, carcinoma cells seed in the liver via the portal venous system. Then, these cells would spread to lung via the inferior vena cava and pulmonary arteries. Finally, the carcinoma cells from lung metastases would seed in other organs via arterial blood [12].

Table 2 Definition of M-stage classifications

\begin{tabular}{ll}
\hline AJCC and ENTES M-stage classifications & Modified M-stage classifications \\
\hline$M_{0}$-stage, no distant metastasis & $\mathrm{mM}_{0}$-stage, no distant metastasis \\
$M_{1}$-stage, distant metastasis & $\mathrm{mM}_{1}$-stage, only liver metastasis \\
& $\mathrm{mM}_{2}$-stage, other single distant organ or two organs metastases \\
& $\mathrm{mM}_{3}$-stage, three or more organs metastases
\end{tabular}


Table 3 Independent Prognostic Factors

\begin{tabular}{|c|c|c|c|c|}
\hline & \multicolumn{2}{|l|}{ Univariate } & \multicolumn{2}{|l|}{ Multivariate } \\
\hline & $\mathrm{HR}$ and $95 \% \mathrm{Cl}$ & $P$-value & $\mathrm{HR}$ and $95 \% \mathrm{Cl}$ & $P$-value \\
\hline \multicolumn{5}{|l|}{ Age (years) } \\
\hline$\leq 60$ & Reference & & Reference & \\
\hline$>60$ & $1.875(1.595-2.204)$ & $<0.001$ & $1.744(1.479-2.055)$ & $<0.001$ \\
\hline \multicolumn{5}{|l|}{ Sex } \\
\hline Male & Reference & & Reference & \\
\hline Female & $0.808(0.691-0.945)$ & 0.008 & $0.850(0.726-0.996)$ & 0.044 \\
\hline \multicolumn{5}{|l|}{ Race } \\
\hline White & Reference & & Reference & \\
\hline Black & $1.345(1.082-1.670)$ & 0.007 & $1.247(0.998-1.558)$ & 0.052 \\
\hline Other & $0.715(0.527-0.970)$ & 0.031 & $0.767(0.565-1.043)$ & 0.090 \\
\hline \multicolumn{5}{|l|}{ Size $(\mathrm{cm})$} \\
\hline$\leq 2$ & Reference & & Reference & \\
\hline$>2$ & $2.889(2.241-3.724)$ & $<0.001$ & $1.322(1.009-1.731)$ & 0.043 \\
\hline Unclear & $6.799(5.110-9.047)$ & $<0.001$ & $1.547(1.129-2.119)$ & 0.007 \\
\hline Primary Site & & & a & \\
\hline Head & Reference & & & \\
\hline Body & $0.684(0.530-0.884)$ & 0.004 & & \\
\hline Tail & $0.682(0.556-0.836)$ & $<0.001$ & & \\
\hline Other & $1.128(0.929-1.368)$ & 0.223 & & \\
\hline \multicolumn{5}{|l|}{ Differentiation } \\
\hline Well & Reference & & Reference & \\
\hline Moderately & $1.557(1.095-2.215)$ & 0.014 & $1.049(0.735-1.498)$ & 0.791 \\
\hline Poorly & 7.414 (5.608-9.803) & $<0.001$ & 3.349 (2.498-4.489) & $<0.001$ \\
\hline Undifferentiated & $9.494(6.113-14.743)$ & $<0.001$ & $3.166(2.000-5.011)$ & $<0.001$ \\
\hline Unclear & $5.136(4.179-6.311)$ & $<0.001$ & $1.626(1.290-2.048)$ & $<0.001$ \\
\hline T-stage & & & a & \\
\hline $\mathrm{T}_{1}$ & Reference & & & \\
\hline $\mathrm{T}_{2}$ & $3.434(2.474-4.766)$ & $<0.001$ & & \\
\hline$T_{3}$ & $3.353(2.399-4.688)$ & $<0.001$ & & \\
\hline $\mathrm{T}_{4}$ & 7.082(4.867-10.306) & $<0.001$ & & \\
\hline Tx & $9.288(6.696-12.882)$ & $<0.001$ & & \\
\hline \multicolumn{5}{|l|}{$\mathrm{N}$-stage } \\
\hline $\mathrm{N}_{0}$ & Reference & & Reference & \\
\hline$N_{1}$ & 1.679 (1.415-1.993) & $<0.001$ & $1.304(1.092-1.557)$ & 0.003 \\
\hline$N x$ & 3.732 (3.019-4.613) & $<0.001$ & $1.452(1.152-1.829)$ & 0.002 \\
\hline \multicolumn{5}{|l|}{ Surgery } \\
\hline Yes & Reference & & Reference & \\
\hline No & $8.556(6.941-10.548)$ & $<0.001$ & $3.901(3.013-5.050)$ & $<0.001$ \\
\hline Unclear & $1.991(0.812-4.883)$ & 0.133 & $1.487(0.601-3.680)$ & 0.391 \\
\hline Radiation & & & a & \\
\hline Yes & Reference & & & \\
\hline No & $1.984(1.511-2.603)$ & $<0.001$ & & \\
\hline Unclear & $0.939(0.420-2.098)$ & 0.878 & & \\
\hline
\end{tabular}


Table 3 Independent Prognostic Factors (Continued)

\begin{tabular}{|c|c|c|c|c|}
\hline & \multicolumn{2}{|l|}{ Univariate } & \multicolumn{2}{|l|}{ Multivariate } \\
\hline & $\mathrm{HR}$ and $95 \% \mathrm{Cl}$ & $P$-value & $\mathrm{HR}$ and $95 \% \mathrm{Cl}$ & $P$-value \\
\hline \multicolumn{5}{|l|}{ mM-stage } \\
\hline $\mathrm{mM}_{0}$-stage & Reference & & Reference & \\
\hline $\mathrm{mM}_{1}$-stage & $4.520(3.789-5.393)$ & $<0.001$ & $1.643(1.339-2.016)$ & $<0.001$ \\
\hline $\mathrm{mM}_{2}$-stage & $8.199(6.380-10.537)$ & $<0.001$ & $2.249(1.704-2.968)$ & $<0.001$ \\
\hline $\mathrm{mM}_{3}$-stage & $16.356(10.266-26.059)$ & $<0.001$ & $5.034(3.110-8.150)$ & $<0.001$ \\
\hline
\end{tabular}

${ }^{a}$ variables excluded by multivariate forward stepwise cox regression

The present study found that with an increasing number of metastatic organs, there was a significant decrease in survival time. In addition, pNENs with liver metastasis had longer overall survival than other single-organ metastatic patterns. However, AJCC and ENETS classify both pNENs with liver metastasis and pNENs with the other metastasitic patterns as $\mathrm{M}_{1}$-stage. Our modified $\mathrm{M}$-stage classification distinguishes that tumor spreading from pancreas only to liver should be separated from the other metastatic patterns, and that it is necessary to design individualized treatment and follow-up programs for patients with lung, bone, or brain metastasis.

Usually, pancreatic resection is not performed when the pancreatic malignant tumor has spread to other organs [13]. However, considering the indolent behavior of pNENs and the high frequency of liver metastasis, several clinicians suggested surgical management could give rise to benefit to pNENs with liver metastasis $[4,14]$. Birnbaum et al. pancreatic resection could slow down tumor growth and reduce hormone production [14], possibly resulting in considerable benefit for patients with liver metastasis [4].

Consistent with previous studies, the tumor size, primary site, differentiation, AJCC T-stage and AJCC $\mathrm{N}$-stage were identified as predictors of distant organ metastasis (Additional file 1: Table S1). Unfortunately, SEER database did not record Ki-67 status and graded the primary tumor only on the basis of morphological description (ICD-O-3) in the pathology report. Thus, we failed to evaluate the predictive role of $\mathrm{Ki}-67$ status and WHO 2010 grading classification (NET G1, NET G2, NET G3 and NEC) in distant organ metastasis.

It seems the primary tumor site is a particularly useful predictor because it is available before any operation occurs. Hao et al. reported that compared to tumors located in the head and neck of the pancreas, tumors in the body and tail showed a decreased risk of liver metastasis in pancreatic adenocarcinoma [15]. In contrast, the present study showed that pNENs located in the pancreatic tail are actually 1.728 times more likely $(P<0.001)$ to develop metastasis, as compared to tumors located in the pancreatic head. This may be due to the fact that patients with pNENs, especially non-functioning pNENs, in the tail of the pancreas are less likely to experience obstructive signs and hormonal symptoms until tumors spread to the peritoneum, spleen, and distant organs $[16,17]$. Thus, at the time of diagnosis, distant organ metastases exist in most of these patients.

Some limitations of the present study should be noted. First, the SEER database only provides information on pNEN metastasis to liver, lung, bone, and brain. The frequency of pNEN metastasis might be underestimated. Second, Hlatky et al. noted that multiple metastatic lesions may be related to a short survival time [18]. However, the SEER database did not collect data on the number of metastatic lesions in each distant organ.

\section{Conclusions}

In conclusion, this is the first population-based study to investigate the metastatic patterns and predictors in advanced pNENs. We found significant differences in survival time across different metastatic patterns. Thus, the modified M-stage classification show a better discriminatory capability than the AJCC and ENETS M-stage classifications. In the future, clinicians should determine individualized treatment and follow-up programs for pNENs with different metastatic patterns.

\section{Additional file}

Additional file 1: Table S1. Clinicopathological characters associated with metastasis. (DOCX $22 \mathrm{~kb}$ )

\section{Abbreviations}

AJCC: American Joint Committee on Cancer; ENETS: European

Neuroendocrine Tumor Society; OS: Overall survival; pNENs: Pancreatic neuroendocrine neoplasms; SD: Standard deviation; SEER: Surveillance, Epidemiology, and End Result

\section{Acknowledgments}

We thank the Surveillance, Epidemiology, and End Results (SEER) program providing the original data. We also thank Prof. Wenli Zhang and Prof. Houli Zhang gave us critical comments during the revision of the manuscript.

\section{Funding}

This work was supported by the National Natural Science Foundation of China [grant number 81473504, 81200989]; China Scholarship Council [grant number 201608080195]. The funders had no any role in the manuscript. 


\section{Availability of data and materials}

The datasets generated and analyzed during the current study are available in the SEER database (https://seer.cancer.gov/).

\section{Authors' contributions}

XZ identified the pNENs from SEER database, designed the study and wrote the manuscript; XZ, JS, MM, PL, LL, YS analyzed and interpreted the data; $Y W$ is responsible for the statistical analyses; PG and LM contributed to conception, design and funding. All authors have been involved in revising and proofreading of the manuscript. All authors listed have approved the manuscript.

\section{Ethics approval and consent to participate}

The original data of our study were provided by SEER database (research data agreement to Xianbin Zhang) and the study protocol was approved by the Ethics Committee of the First Affiliated Hospital of Dalian Medical University (approval number: YJ-KY-FB-2017-05).

\section{Consent for publication}

Not applicable.

\section{Competing interests}

The authors declare that they have no competing interests.

\section{Publisher's Note}

Springer Nature remains neutral with regard to jurisdictional claims in published maps and institutional affiliations.

\section{Author details}

'The First Affiliated Hospital of Dalian Medical University, Zhongshan 222, Dalian 116011, China. ${ }^{2}$ Institute for Experimental Surgery, Rostock University Medical Center, Schillingallee 69a, 18057 Rostock, Germany. ${ }^{3}$ Department of Epidemiology, Dalian Medical University, Lvshun West 9, Dalian 116044 China. ${ }^{4}$ Department of Evidence-based Medicine and Statistics, the First Affiliated Hospital of Dalian Medical University, Zhongshan 222, Dalian 116011, China. ${ }^{5}$ Department of General Surgery, the Shenzhen University General Hospital and Shenzhen University School of Medicine, Xueyuan 1098, Shenzhen 518055, China. ${ }^{6}$ Department of Epidemiology, Dalian Medical University, Zhongshan Road 222, Dalian 116011, China.

Received: 18 January 2018 Accepted: 3 October 2018

Published online: 19 October 2018

\section{References}

1. Dasari A, Shen C, Halperin D, et al. Trends in the incidence, prevalence, and survival outcomes in patients with neuroendocrine tumors in the United States. JAMA Oncol. 2017:3:1335-42.

2. Panzuto F, Boninsegna L, Fazio N, et al. Metastatic and locally advanced pancreatic endocrine carcinomas: analysis of factors associated with disease progression. J Clin Oncol. 2011:29:2372-7.

3. Zhang $X$, Lu L, Shang $Y$, et al. The number of positive lymph node is a better predictor of survival than the lymph node metastasis status for pancreatic neuroendocrine neoplasms: a retrospective cohort study. Int J Surg. 2017;48:142-8.

4. Jin $\mathrm{K}, \mathrm{Xu} J$, Chen J, et al. Surgical management for non-functional pancreatic neuroendocrine neoplasms with synchronous liver metastasis: a consensus from the Chinese study Group for Neuroendocrine Tumors (CSNET). Int Oncol. 2016;49:1991-2000.

5. Garcia-Carbonero R, Rinke A, Valle JW, et al. ENETS consensus guidelines for the standards of care in neuroendocrine neoplasms. Systemic therapy 2 : chemotherapy. Neuroendocrinology. 2017;105:281-94.

6. Chamberlain RS, Canes D, Brown KT, et al. Hepatic neuroendocrine metastases: does intervention alter outcomes? Am Coll Surg. 2000;190:432-45.

7. Vatandoust S, Price TJ, Karapetis CS. Colorectal cancer: metastases to a single organ. World J Gastroenterol. 2015;21:11767-76.

8. Bando E, Makuuchi R, Tokunaga M, et al. Impact of clinical tumor-nodemetastasis staging on survival in gastric carcinoma patients receiving surgery. Gastric Cancer. 2017;20:448-56.

9. Niederle MB, Hackl M, Kaserer K, et al. Gastroenteropancreatic neuroendocrine tumours: the current incidence and staging based on the WHO and European neuroendocrine tumour society classification: an analysis based on prospectively collected parameters. Endocr Relat Cancer 2010;17:909-18.

10. Lawrence B, Gustafsson Bl, Chan A, et al. The epidemiology of gastroenteropancreatic neuroendocrine tumors. Endocrinol Metab Clin N Am. 2011:40:1-18

11. Pavel M, Costa F, Capdevila J, et al. ENETS consensus guidelines update for the management of distant metastatic disease of intestinal, pancreatic, bronchial neuroendocrine neoplasms (NEN) and NEN of unknown primary site. Neuroendocrinology. 2016;103:172-85.

12. Weiss L, Grundmann E, Torhorst J, et al. Haematogenous metastatic patterns in colonic carcinoma: an analysis of 1541 necropsies. J Pathol. 1986;150:195-203.

13. Partelli S, Bartsch DK, Capdevila J, et al. ENETS consensus guidelines for standard of care in neuroendocrine tumours: surgery for small intestinal and pancreatic neuroendocrine tumours. Neuroendocrinology. 2017;105:255-65.

14. Birnbaum DJ, Turrini O, Vigano $L$, et al. Surgical management of advanced pancreatic neuroendocrine tumors: short-term and long-term results from an international multi-institutional study. Ann Surg Onco. 2015;22:1000-7.

15. S D LW, GY B, et al. Risk factors of liver metastasis from advanced pancreatic adenocarcinoma: a large multicenter cohort study. World J Surg Oncol. 2017:15:120.

16. Freelove $R$, Walling AD. Pancreatic cancer: diagnosis and management. Am Fam Physician. 2006:73:485-92.

17. Zhang $X, M a L, B a o H$, et al. Clinical, pathological and prognostic characteristics of gastroenteropancreatic neuroendocrine neoplasms in China: a retrospective study. BMC Endocr Disord. 2014;14:54.

18. Hlatky R, Suki D, Sawaya R. Carcinoid metastasis to the brain. Cancer. 2004; 101:2605-13.

\section{Ready to submit your research? Choose BMC and benefit from:}

- fast, convenient online submission

- thorough peer review by experienced researchers in your field

- rapid publication on acceptance

- support for research data, including large and complex data types

- gold Open Access which fosters wider collaboration and increased citations

- maximum visibility for your research: over $100 \mathrm{M}$ website views per year

At BMC, research is always in progress.

Learn more biomedcentral.com/submissions 